\title{
Comparison of Anticancer Effects of Carvone, Carvone- Rich Essential Oils, and Chitosan Nanoparticles Containing Each of Them
}

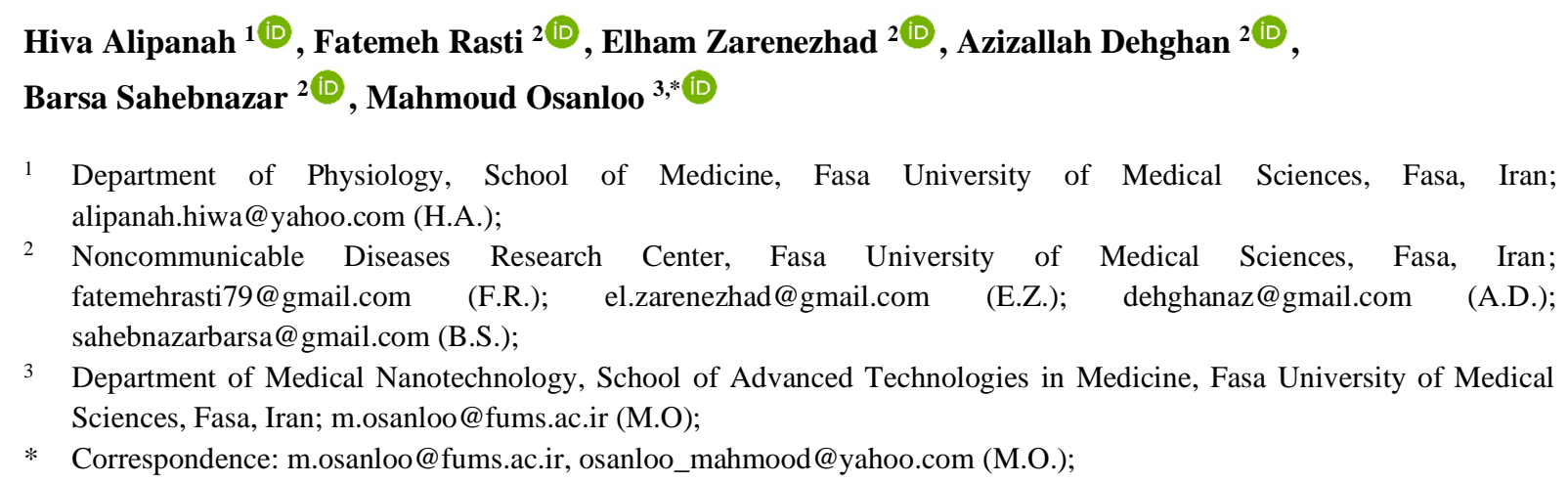

Received: 31.08.2021; Revised: 10.10.2021; Accepted: 12.10.2021; Published: 21.10.2021

\begin{abstract}
Cancers were the first cause of death in 2020; breast and skin are two common cancers worldwide. The most common cancer treatment approach is still chemotherapy; however, as side effects and multidrug resistance, the development of green nano drugs has received much attention. In this study, the chemical composition of Mentha spicata and Tanacetum balsamita essential oils was first investigated. The anticancer effects of them and carvone (as their major ingredients) were then evaluated on human melanoma (A375) and breast cancer (MDA-MB468) cells. After that, an attempt was made to improve their efficacies by preparing chitosan nanoparticles containing each of them. The efficacies of nanoformulations showed a significant improvement $(\mathrm{p}<0.05)$ compared to their nonformulated states. The best-observed potency was related to chitosan nanoparticles containing $T$. balsamita essential oil with a particle size of $195 \pm 7 \mathrm{~nm}$; IC 50 values against A375 and MDA-MB468 were observed at 85.3 and $240.1 \mu \mathrm{g} / \mathrm{mL}$. Thus, the nanoformulation with green ingredients could be considered a proper candidate for further consideration in vivo studies.
\end{abstract}

Keywords: Mentha spicata; Tanacetum balsamita; melanoma; breast cancer

(C) 2021 by the authors. This article is an open-access article distributed under the terms and conditions of the Creative Commons Attribution (CC BY) license (https://creativecommons.org/licenses/by/4.0/).

\section{Introduction}

Cancer with around 10 million deaths is a leading cause of death worldwide in 2020 [1, 2]. Breast cancer with 2.26 million cases and skin cancer (non-melanoma and melanoma) with around 1.5 million are the first and fifth common types of cancer [3]. Besides, they caused 685000 and 121000 death only in 2020 [3, 4]. Despite the rising cancer rate, common treatment approaches like chemotherapy, surgery, and radiotherapy were underdeveloped; they also have side effects [5, 6]. Therefore, the development of new anticancer agents is crucial.

The use of plant-derived substances, especially essential oils (EOs), is a promising approach for bypassing the side effects of chemotherapy agents [7]. However, the efficacy of EOs is generally less than synthetic drugs. The preparation of nanostructures containing EOs (nanofibers, nanoparticles, and lipid nanocarriers) has thus been recently proposed as a 
practical solution to improve their efficacies $[8,9]$. Nowadays, chitosan nanoparticles, as a naturally biocompatible and biodegradable polymer, have been widely used in drug delivery studies [10, 11]. For instance, chitosan nanoparticles containing Torreya grandis EO with a particle size of $349.6 \mathrm{~nm}$ were proposed; it showed a more potent antibacterial agent than nonformulated EO [12]. In another research, Carum copticum EO was successfully loaded in chitosan nanoparticles with 30-80 nm diameter; the nanoparticles showed more antioxidant effect than EO [13].

Mentha spicata L. and Tanacetum balsamita L. are two important medicinal plants with a broad range of biological effects [7, 14]. For instance, $M$. spicata is used as a diuretic, antispasmodic, and anti-flatulent and controls respiratory and gastrointestinal ailments [15]. Some previous studies also reported antiproliferative effects of $M$. spicata on particular breast cancer cell lines (e.g., MCF7, Wehi-16, U937, and KB), fibrosarcoma, leukemic monocyte, and mouth epidermal carcinoma [16-19]. Moreover, anticancer effects (LD50) of M. spicata EO against different human-derived tumor cell lines, including T47D, HCT116, and MCF7, were reported at 324, 279, and $975(\mu \mathrm{g} / \mathrm{mL})$ [20]. Also, Bradaweel et al. evaluated antiproliferative activities associated with the $M$. spicata against three human cancer cell lines (e.g., T47D, HCT116, and MCF7) [20]. In addition, many studies introduced clinical functions for T. balsamita, such as spasmolytic and diuretic roles [7]. Moreover, anti-inflammatory and analgesic effects of $T$. balsamita EO in a rat model were also reported [21]. Due to the medicinal properties of $T$. balsamita and $M$. spicata EOs, a new trend could develop anticancer agents using their major ingredients, i.e., carvone $[14,15]$. From the literature, carvone as an active component could induce caspase-mediated cell death in breast cancer cells such as MCF7 and MDA-MB231, gastric cancer AGS cells, and colon cancer cells (HT29 and SW480) [22-24].

In the current study, the anticancer effects of carvone, T. balsamita, M. spicata were first investigated against a human melanoma cell line (A375) and a human breast cancer cell line (MDA-MB468). An attempt was then made to improve their efficacies by preparing chitosan nanoparticles containing each.

\section{Materials and Methods}

\subsection{Materials.}

MDA-MB468 (ATCC HTB132) and A375 (ATCC CRL1619) cell lines were obtained from the Pasteur Institute of Iran. Tripolyphosphate, chitosan low molecular weight (75-85\% de-acetylation degree), carvone, and tween 20 were bought from Sigma-Aldrich (USA). $M$. spicata and T. balsamita EOs were purchased from Pharmaceutical Company Essential Oil Dr. Soleimani (Iran).

\subsection{Chemical compositions of the Eos.}

Ingredients of $M$. spicata and $T$. balsamita EOs were identified by a Gas Chromatograph as described in our previous study [25].

\subsection{EOs or carvone chitosan nanoparticles preparation.}

We used the ionic gelation to prepare chitosan nanoparticles containing carvone or EOs as described in our previous study with a slight modification [26]. In the beginning, chitosan 
powder $(0.25 \% \mathrm{w} / \mathrm{v})$ was dissolved at $2000 \mathrm{rpm}$ in acetic acid $1 \%$ (an aqueous solution) at ambient temperature. The solution was then centrifuged (30 min, $7000 \mathrm{rpm}$ ) to precipitate undissolved chitosan. Next, carvone, M. spicata, and T. balsamita EOs were dissolved $(0.5 \%$ $\mathrm{w} / \mathrm{v})$ in the prepared chitosan solution containing tween $20(0.5 \% \mathrm{w} / \mathrm{v})$ separately; the obtained solutions were then stirred for $10 \mathrm{~min}$ at $2000 \mathrm{rpm}$. Finally, we added tripolyphosphate solution $(0.15 \% \mathrm{w} / \mathrm{w})$ using a syringe pump $(1 \mathrm{~mL} / \mathrm{h})$ and stirred for $40 \mathrm{~min}$. The prepared nanoformulations were abbreviated CVChiNPs, MSChiNPs, and TBChiNPs, and used for characterizations and MTT assays.

\subsection{Size analyses.}

The particle size of CVChiNPs, MSChiNPs, and TBChiNPs was investigated by Dynamic Light Scattering (DLS; 9900 series; K-One Nano Ltd; Korea). Particle size distribution (SPAN) of them were calculated using equation $D 90-D 10 / D 50$. D is diameter, 90,50 , and 10 are a percentage of particles with lower diameters than these defined values.

\subsection{Investigation loading of carvone, M. spicata, and T. balsamita EOs in chitosan} nanoparticles.

Attenuated Total Reflection-Fourier Transform Infrared (ATR-FTIR) was used to characterize functional groups and confirm the samples' successful loading in the chitosan nanoparticles. Free chitosan nanoparticles, carvone, M. spicata EO, T. balsamita EO, and their nano-formulated states (CVChiNPs, MSChiNPs, and TBChiNPs) were subjected to ATRFTIR instruments without any preparation process. Spectra were recorded $\left(400-4000 \mathrm{~cm}^{-1}\right)$ using the device (Tensor II, Bruker, Germany).

\subsection{MTT assay.}

The anticancer effects of carvone, M. spicata EO, T. balsamita EO, CVChiNPs, MSChiNPs, and TBChiNPs were investigated using the MTT cell proliferation assay as described in our previous study [26]. Briefly, carvone, M. spicata, and T. balsamita were first dissolved in the phosphate-buffered saline solution with $0.5 \%(\mathrm{w} / \mathrm{v}) \mathrm{DMSO}$, equal to the asprepared nanoformulations. Then, seeded cells (MDA-MB468 and A375) in 96-well culture plates containing $75 \mu \mathrm{L}$ DMEM complete medium (10\% FBS and $1 \%$ penicillin/streptomycin) were treated with different amounts of samples to reach concentrations of 1200, 600, 300, 150, and $75 \mu \mathrm{g} / \mathrm{mL}$. After 24 hours of incubation, nanoformulations' milky color of wells were first washed with PBS, and $100 \mu \mathrm{L} /$ well of MTT solution $0.5 \mu \mathrm{g} / \mathrm{mL}$ was then added. After 4 hours of incubation, $100 \mu \mathrm{L} /$ well DMSO was added for formazan solubilization. Cell viability at different concentrations was calculated by comparing the optical density of control groups (no treated) and treated using at $570 \mathrm{~nm}$.

\section{Results}

\subsection{Constituents of M. spicata and T. balsamita Eos.}

Identified compounds in M. spicata and T. balsamita EOs with a high portion than $1 \%$ are listed in Table 1; they comprised $90.6 \%$ of all identified components in M. spicata and $84.3 \%$ in T. balsamita. Besides, carvone was the major ingredient in both; 37.2 and $36.3 \%$. 
Table 1. Chemical ingredients (> 1\%) identified in the EOs by Gas Chromatography-Mass Spectrometry analysis.

\begin{tabular}{|c|c|c|c|c|c|}
\hline \multirow{2}{*}{$\begin{array}{l}\text { Retention } \\
\text { index }\end{array}$} & \multirow{2}{*}{ Compounds } & \multicolumn{2}{|c|}{ M. spicata } & \multicolumn{2}{|c|}{ T. balsamita } \\
\hline & & Area & $\%$ & Area & $\%$ \\
\hline 931 & $\alpha$-pinene & 82848781 & 2.5 & --- & --- \\
\hline 949 & comphene & 44325854 & 1.3 & --- & --- \\
\hline 970 & sabinene & 63810507 & 1.9 & --- & --- \\
\hline 976 & $\beta$-pinene & 110567647 & 3.4 & --- & --- \\
\hline 1023 & $p$-cymene & --- & --- & 45489319 & 1.3 \\
\hline 1025 & 1,8 -cineole & --- & --- & 67090832 & 2.0 \\
\hline 1026 & limonene & 936146024 & 28.5 & 125222965 & 3.7 \\
\hline 1101 & $\alpha$-thujone & --- & --- & 90781085 & 2.7 \\
\hline 1113 & $\beta$-thujone & --- & --- & 458741960 & 13.4 \\
\hline 1121 & trans-p-mentha-2,8-dien-1-ol & --- & --- & 45749024 & 5.3 \\
\hline 1159 & iso-borneol & --- & --- & 39407708 & 1.2 \\
\hline 1168 & borneol & 130589576 & 4.0 & --- & --- \\
\hline 1187 & $\alpha$-terpineol & 66211461 & 2.0 & --- & --- \\
\hline 1191 & cis-dihydro carvone & --- & --- & 61508804 & 1.9 \\
\hline 1193 & dihydrocarveol neo & 88471507 & 2.7 & --- & --- \\
\hline 1215 & trans-carveol & --- & --- & 39066428 & 1.1 \\
\hline 1234 & pulegone & 108555599 & 3.3 & --- & --- \\
\hline 1243 & carvone & 1221316667 & 37.2 & 1238470188 & 36.3 \\
\hline 1342 & piperitenone & 87099203 & 2.7 & --- & --- \\
\hline 1418 & trans-caryophyllene & 34507802 & 1.1 & --- & --- \\
\hline 1480 & Germacrene D & --- & --- & 73253122 & 2.1 \\
\hline 1493 & zingiberene & --- & --- & 46200785 & 1.4 \\
\hline 1504 & $\beta$-bisabolene & --- & --- & 147778675 & 4.3 \\
\hline 1522 & $\delta$-cadinene & --- & --- & 55973474 & 1.6 \\
\hline 1560 & germacrene B & --- & --- & 32966540 & 1.0 \\
\hline 1641 & tau-muurolol & --- & $\begin{array}{ll}-- \\
-\end{array}$ & 53704860 & 1.6 \\
\hline 1966 & ilicic acid methyl ester & --- & --- & 58607545 & 1.7 \\
\hline Total & & & 90.6 & & 84.3 \\
\hline
\end{tabular}

3.2. Particle size and particle size distribution of CVChiNPs, MSChiNPs, and TBChiNPs.

DLS diagrams of CVChiNPs, MSChiNPs, and TBChiNPs with particle sizes of $217 \pm$ 9, $161 \pm 4$, and $195 \pm 7 \mathrm{~nm}$ are depicted in Figure 1. Their SPAN values were obtained as 0.89 , 0.92, and 0.91; their narrow particle size distributions are confirmed since SPAN values are less than 1 [27]. In addition, the presence of a peak sharp in all three nanoformulations also indicates their narrow particle size distribution.

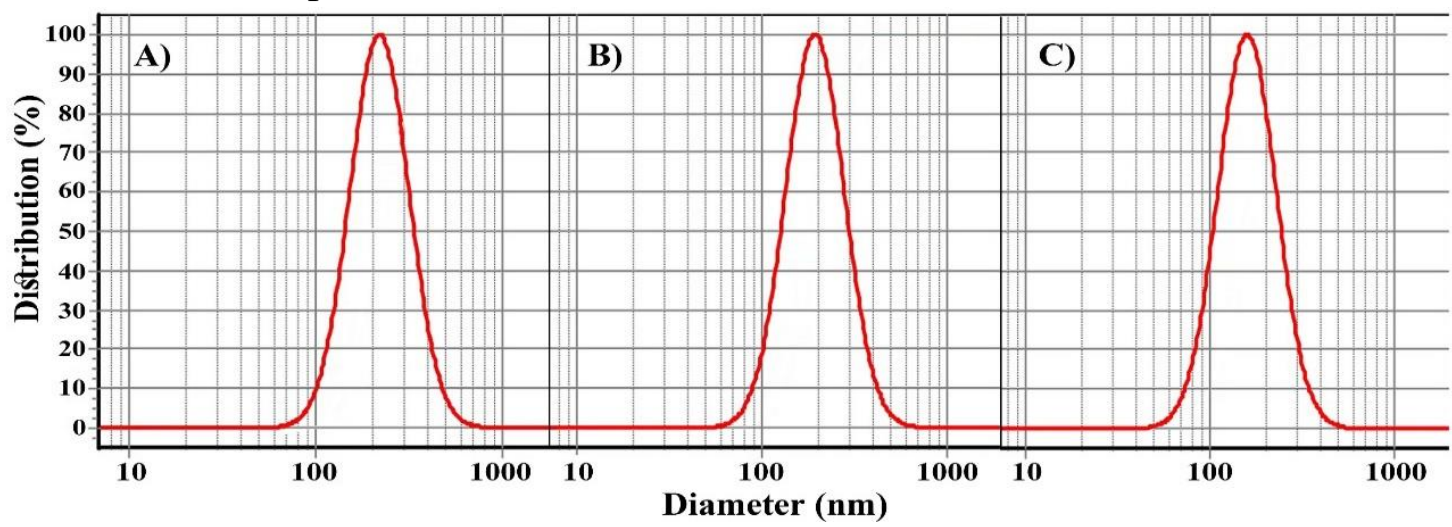

Figure 1. DLS diagrams of chitosan nanoparticles containing-carvone $(A=217 \pm 9 \mathrm{~nm}),-M$. spicata $\mathrm{EO}(\mathrm{B}=$ $161 \pm 4 \mathrm{~nm})$, and $-T$. balsamita $\mathrm{EO}(\mathrm{C}=195 \pm 7 \mathrm{~nm})$.

\subsection{Loading of carvone and EOs in chitosan nanoparticles.}

In Figure 2A, the sharp peak at $1700 \mathrm{~cm}^{-1}$ attributed to $\mathrm{C}=\mathrm{O}$ (stretching) could be related to the carbonyl group in tween and chitosan. The strong band at $1094 \mathrm{~cm}^{-1}$ corresponds to symmetric and anti-symmetric phosphodioxy $\left(\mathrm{PO}_{2}\right)$ structure, and the characteristic peak at 
about $1020 \mathrm{~cm}^{-1}$ relates to anti-symmetric and symmetric stretching in the phosphite $\left(\mathrm{PO}_{3}\right)$ structure. In addition, two new peaks at 1280 and $1152 \mathrm{~cm}^{-1}$ have appeared after the crosslinking process. They belong to anti-symmetric stretching vibrations of $\mathrm{PO}_{2}$ groups in tripolyphosphate ions; they confirm the ionic links between $\left(\mathrm{NH}_{3}{ }^{+}\right)$chitosan and anionic structure in tripolyphosphate [26]. The ATR-FTIR spectrum of pure carvone (Figure 2B) shows the band at $3083 \mathrm{~cm}^{-1}$ related to the stretching vibration of $=\mathrm{C}-\mathrm{H}$, and the bands at 2970, 2922, and $2886 \mathrm{~cm}^{-1}-\mathrm{CH}$ stretching vibration. The characteristic band at $1668 \mathrm{~cm}^{-1}$ relates to stretching vibration of $\mathrm{C}=\mathrm{O}$, the peak at $1644 \mathrm{~cm}^{-1}$ corresponding to $\mathrm{C}=\mathrm{C}$ stretching. Moreover, the peak at $1365 \mathrm{~cm}^{-1}$ relates to $\mathrm{CH}_{3}$, and the band at $1109 \mathrm{~cm}^{-1}$ relates to $\mathrm{C}-\mathrm{O}$ bending vibration. In Figure 2C, approximately most carvone characteristic bands are seen in the spectrum of CVChiNPs, similar to small wavenumber changes. Two strong peaks were shown at $1544 \mathrm{~cm}^{-}$ ${ }^{1}$ (C-O-C) and $1281 \mathrm{~cm}^{-1}$ (amide II), which can be related to the complex preparation with electrostatic linking between $\left(\mathrm{NH}_{3}{ }^{+}\right)$structure of chitosan and phosphoric groups of tripolyphosphate within the chitosan nanoparticles [26].

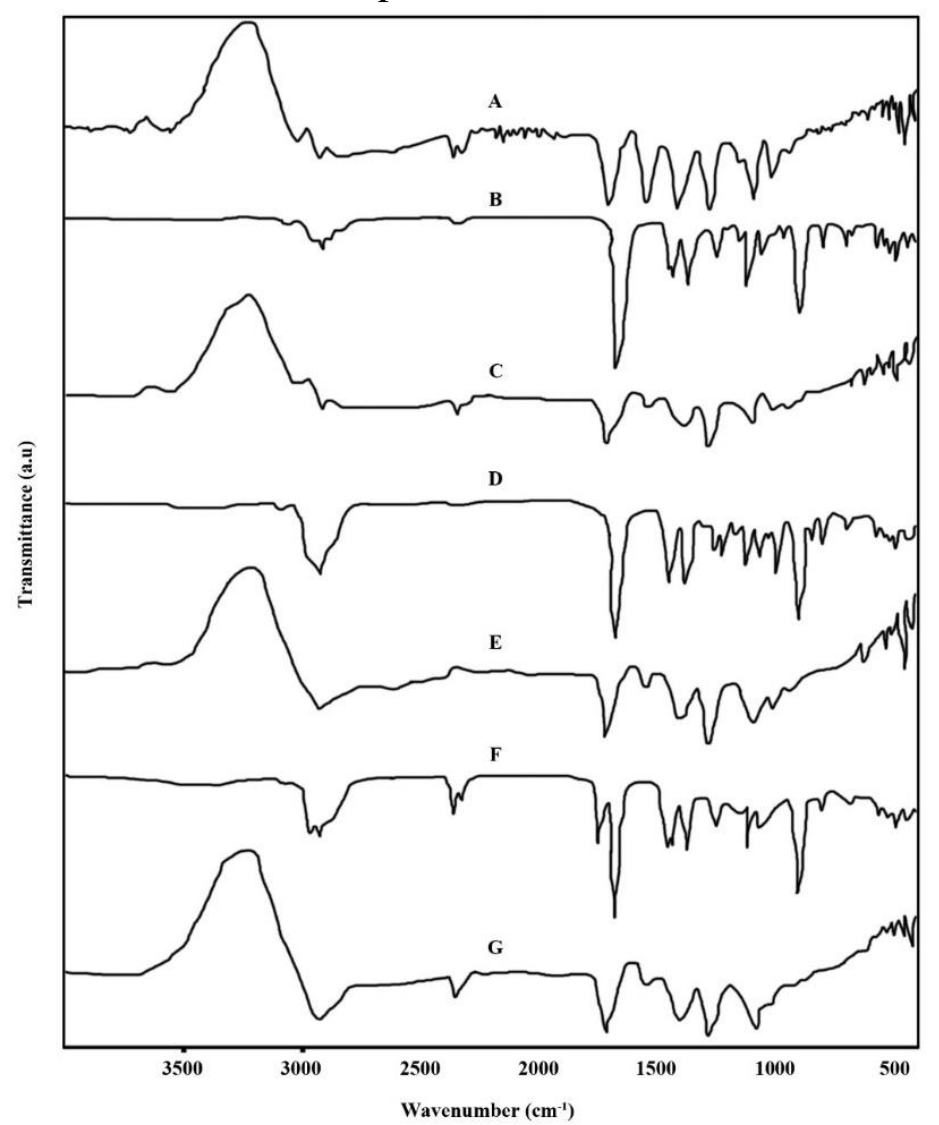

Figure 2. ATR-FTIR analyses of free chitosan nanoparticles (A), carvone (B), chitosan nanoparticles containing carvone (CVChiNPs) (C), M. spicata EO (D), chitosan nanoparticles containing M. spicata EO (MSChiNPs)

(E), T. balsamita EO (F), and chitosan nanoparticles containing T. balsamita EO (TBChiNPs) (G).

In Figure 2D, the ATR-FTIR spectrum of pure $M$. spicata is displayed; the wideband at around $3462 \mathrm{~cm}^{-1}$ can be corresponding to hydroxyl groups, and the band at $3075 \mathrm{~cm}^{-1}$ attributed to $=\mathrm{C}-\mathrm{H}$ (stretching vibration). The peaks at 2965 and $2922 \mathrm{~cm}^{-1}$ showed $-\mathrm{CH}$ stretching vibration, the sharp band at $1712 \mathrm{~cm}^{-1}$ corresponding to $\mathrm{C}=\mathrm{O}$, and the band at 1674 $\mathrm{cm}^{-1}$ is attributed to $\mathrm{C}=\mathrm{C}$ stretching. The peak at $1373 \mathrm{~cm}^{-1}$ is related to $\mathrm{CH}_{3}$, and the band at $1016 \mathrm{~cm}^{-1}$ relates to $\mathrm{C}-\mathrm{O}$ bending vibration. In Figure $2 \mathrm{E}$, the two strong bands at $1555 \mathrm{~cm}^{-1}$ (C-O-C) and $1230 \mathrm{~cm}^{-1}$ (amide II) can be related to the complex preparation between $\mathrm{NH}_{3}{ }^{+}$ groups chitosan and anionic structure tripolyphosphate. Furthermore, all the characteristic 
peaks appear in the spectrum of $M$. spicata EO at the same wavenumber; the results indicate that the EO was successfully loaded in MSChiNPs.

The ATR-FTIR spectrum of pure T. balsamita EO is displayed in Figure 2F; the broad peak at about $3620 \mathrm{~cm}^{-1}$ can be corresponding to hydroxyl groups, and the peak at $3079 \mathrm{~cm}^{-1}$ is related to $=\mathrm{C}-\mathrm{H}$ (stretching vibration). The peaks at 2958 and $2924 \mathrm{~cm}^{-1}$ demonstrated $-\mathrm{CH}$ stretching vibration, the peak at $1712 \mathrm{~cm}^{-1}$ can be attributed to $\mathrm{C}=\mathrm{O}$, and the band at $1645 \mathrm{~cm}^{-}$ ${ }^{1}$ is related to $\mathrm{C}=\mathrm{C}$ stretching. The band at $1366 \mathrm{~cm}^{-1}$ corresponded to $\mathrm{CH}_{3}$, and the peak at $1110 \mathrm{~cm}^{-1}$ is attributed to $\mathrm{C}-\mathrm{O}$ bending vibration. In Figure $2 \mathrm{G}$, the ATR-FTIR spectrum of TBChiNPs showed a sharp band at $1280 \mathrm{~cm}^{-1}$ belonging to $\mathrm{C}-\mathrm{N}$ stretching that confirmed the complex preparation whit linking electrostatic between $\mathrm{NH}_{3}{ }^{+}$groups of chitosan and anionic groups of tripolyphosphate. The peak around $1543 \mathrm{~cm}^{-1}$ can correspond to $\mathrm{C}-\mathrm{N}$ stretching and relates to the amide structure. All the other peaks appear in the spectrum of T. balsamita EO at the same wavenumber; it could be confirmed that the EO was encapsulated into TBChiNPs.

\subsection{Anticancer effects of carvone, M. spicata EO, and T. balsamita EO versus chitosan} nanoparticles containing them.

Anticancer effects of carvone, $M$. spicata EO, and T. balsamita EO versus chitosan nanoparticles containing them against A375 cells were observed in a dose-dependent manner (Figure 3). Interestingly, the viability of cells after treatment with CVChiNPs and TBChiNPs at three concentrations of 300,600 , and $1200 \mu \mathrm{g} / \mathrm{mL}$ were reduced to $\leq 15 \%$. Moreover, nanoformulations at all concentrations indicated more anticancer effects than their nonformulated states $(p<0.05)$.

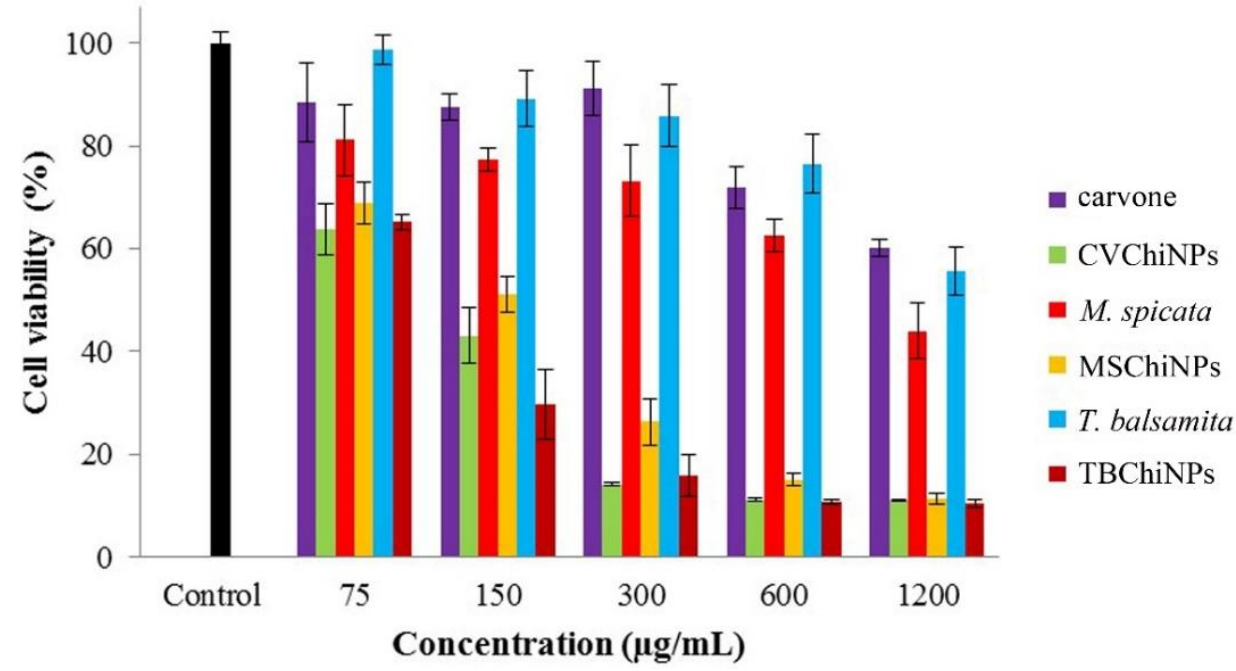

Figure 3. Anticancer effects of carvone, M. spicata EO, and T. balsamita EO versus chitosan nanoparticles containing them (CVChiNPs, MSChiNPs, and TBChiNPs) against A375 cells. Data are mean \pm SD $(n=3)$.

Figure 4 indicated the dose-dependent effects of the samples on the MDA-MB468 cells line. However, this cell line showed less sensitivity to the samples than A375 cells; only at the highest concentration of nanoformulations $(1200 \mu \mathrm{g} / \mathrm{mL})$ was cell viability decreased to less than $10 \%$. Moreover, M. spicata at three concentrations $(75,150$, and $300 \mu \mathrm{g} / \mathrm{mL})$ showed more potency than its nano-formulated states (MSChiNPs) $(p<0.05)$; however, at two highest concentrations (600, and 1200) efficacy of MSChiNPs was more potent $(p<0.05)$. In the other two samples, nanoformulations at four concentrations $(150-1200 \mu \mathrm{g} / \mathrm{mL})$ indicated significantly more anticancer effects than their non-formulated states $(p<0.05)$. 


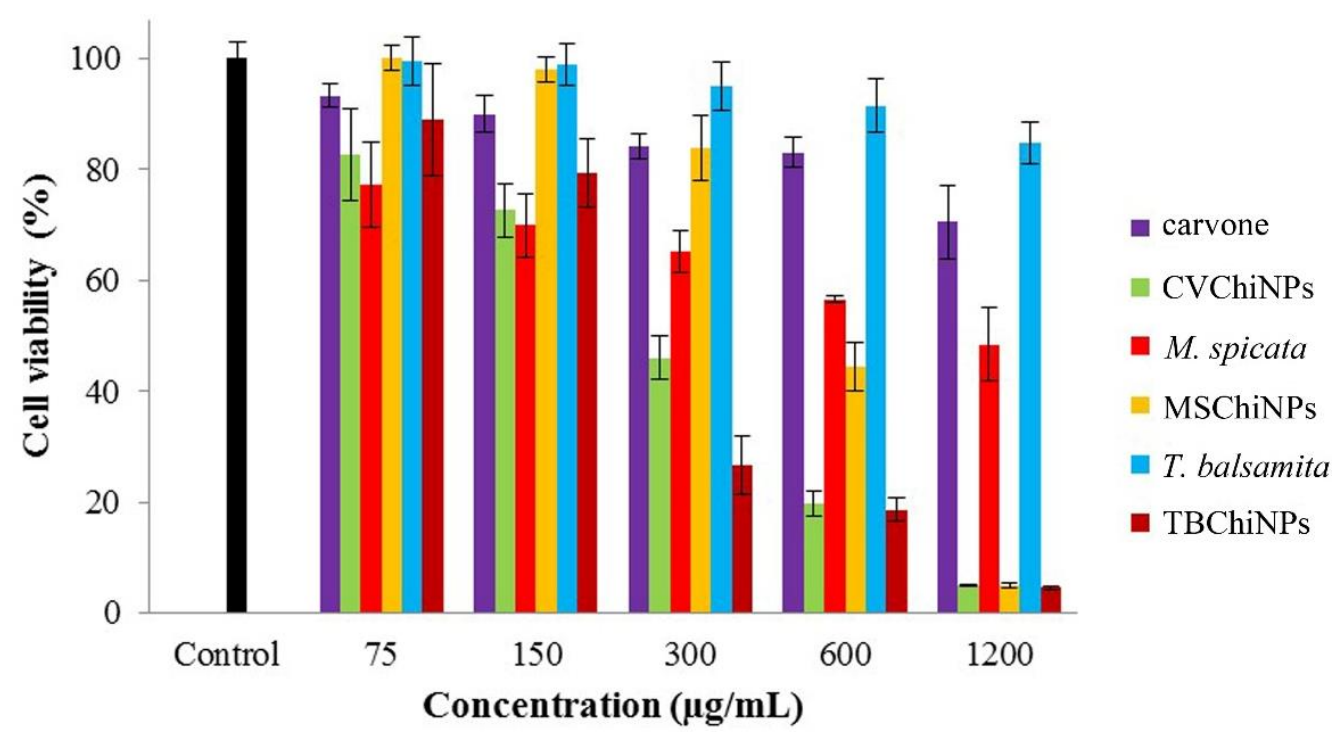

Figure 4. Anticancer effects of carvone, M. spicata EO, and T. balsamita EO versus chitosan nanoparticles containing them (CVChiNPs, MSChiNPs, and TBChiNPs) against MDA-MB468 cells. Data are mean \pm SD (n $=3$ ).

Anticancer effects $\left(\mathrm{IC}_{50}\right)$ of samples against $\mathrm{A} 375$ and MDA-MB468 cells are listed in Table 2. IC 50 values of all nanoformulations against A375 and MDA-MB468 were significantly more potent than their non-formulated states $(p<0.05)$. Moreover, TBChiNPs with $\mathrm{IC}_{50}$ values of 85.3 and $240.1 \mu \mathrm{g} / \mathrm{mL}$ showed the best efficacy against both cell lines.

Table 2. Anticancer effects of carvone, M. spicata EO, and T. balsamita EO versus chitosan nanoparticles containing them (CVChiNPs, MSChiNPs, and TBChiNPs) against MDA-MB468 and A375 cells.

\begin{tabular}{|c|c|c|c|c|}
\hline \multirow{3}{*}{ Samples } & \multicolumn{2}{|l|}{ A375 } & \multicolumn{2}{|c|}{ MDA-MB468 } \\
\hline & \multicolumn{2}{|l|}{$\mathrm{IC}_{50}{ }^{\mathrm{a}}$} & \multicolumn{2}{|c|}{$\mathrm{IC}_{50}$} \\
\hline & $\mathbf{L C L}^{\mathrm{b}}$ & $\mathrm{UCL}^{\mathrm{c}}$ & LCL & UCL \\
\hline \multirow{2}{*}{ carvone } & \multicolumn{2}{|l|}{3657.4} & \multicolumn{2}{|c|}{6038.0} \\
\hline & 448 & 29826 & 2931 & 12435 \\
\hline \multirow{2}{*}{ CVChiNPs } & \multicolumn{2}{|l|}{99.1} & \multicolumn{2}{|l|}{236.2} \\
\hline & 50 & 195 & 198 & 281 \\
\hline \multirow{2}{*}{ M. spicata EO } & \multicolumn{2}{|l|}{1136.2} & \multicolumn{2}{|c|}{1067.7} \\
\hline & 675 & 1911 & 939 & 1213 \\
\hline \multirow{2}{*}{ MSChiNPs } & \multicolumn{2}{|l|}{143.4} & \multicolumn{2}{|l|}{514.6} \\
\hline & 112 & 182 & 466 & 567 \\
\hline \multirow{2}{*}{ T. balsamita EO } & \multicolumn{2}{|l|}{1312.1} & \multicolumn{2}{|c|}{2323.6} \\
\hline & 687 & 2503 & 1007 & 5357 \\
\hline \multirow{2}{*}{ TBChiNPs } & \multicolumn{2}{|l|}{85.3} & \multicolumn{2}{|l|}{240.1} \\
\hline & 41 & 177 & 192 & 299 \\
\hline
\end{tabular}

${ }^{\mathrm{a}}$ Inhibitory Concentration 50\% ( $\left.\mu \mathrm{g} / \mathrm{mL}\right) ;{ }^{\mathrm{b}}$ Lower Confidence Limit (95\%); ${ }^{\mathrm{c}}$ Upper Confidence Limit (95\%).

\section{Discussions}

In developing new drugs, preclinical models such as in vitro human cell lines should be first performed to find effective chemo-preventive/therapeutic agents [28-30]. The selection of the targeted cell line is also important. For example, as may be expected from genetic, morphologic, and phenotypic evidence, the A375 cell line is a more aggressive and metastatic cancer with poor chemotherapy responsiveness, which could be an effective evaluation model for anti-melanoma cancer agents [31,32]. On the other hand, highly heterogeneous cancer such as the MDA-MB468 cell line is an in vitro cancer cell model without estrogen, progesterone, and HER2 receptors (a triple-negative breast cancer cell model). It is commonly used in research on proliferation, metastasis, migration, and chemical breast cancer treatments [33, 34]. Thus these two cell lines were used in the current study. 
As listed in Table 1, the only component found in the M. spicata and T. balsamita EOs was carvone; it contained about $37 \%$ of both. The most important issue that is not yet well clarified is whether the biological potency of EOs is due to their main ingredient(s) or the whole oils as complex mixtures. From the literature, it seems that more potency of an EO or component strongly depends on the organism under study. For instance, $\mathrm{IC}_{50}$ values of clove EO against Klebsiella pneumoniae, Pseudomonas aeruginosa, and Staphylococcus aureus did not significantly differ with eugenol (its major ingredient); the difference against Escherichia coli was only significant. Moreover, no significant difference was observed between the effects of clove EO and eugenol against Leishmania major and Leishmania tropica [25]. Nevertheless, the current study results did not specify anything; both EOs and carvone against A375 cells were not significantly different together $(p>0.05)$ : although the efficacy of EOs was relatively more potent than carvone. However, the results were quite different for MDA-MB468 cells. The $\mathrm{IC}_{50}$ value of $M$. spicata $(1067 \mu \mathrm{g} / \mathrm{mL})$ was more potent than $T$. balsamita $(2323 \mu \mathrm{g} / \mathrm{mL})$; however, this difference was not statistically significant $(p>0.05)$. Besides, M. spicata EO was significantly more potent $(p<0.05)$ than carvone $(6038 \mu \mathrm{g} / \mathrm{mL})$.

In the current study, an attempt was made to improve the anticancer effects of carvone, T. balsamita, and M. spicata EOs by preparing chitosan nanoparticles containing each of them. No report was found on preparing any nanoformulation of $T$. balsamita $\mathrm{EO}$ in the literature. However, some nanoformulation on M. spicata EO has been reported; its nanoemulsion with a droplet size of $97.8 \mathrm{~nm}$ was prepared as green larvicide against Culex pipiens and Musca domestica [35]. Furthermore, in a report, chitosan coating containing M. spicata EO was proposed as active packaging material with proper antibacterial against Listeria monocytogenes to preserve fresh strawberries [36]. Besides, such proposed coating also showed antibacterial effects against some species of Pseudomonas [37]. Furthermore, in another research, $M$. spicata extract as an antioxidant agent was successfully capsulated in chitosan nanoparticles [38]. Moreover, its aqueous extract was also used as a reducing agent for the green synthesis of silver nanoparticles $(350-500 \mathrm{~nm})$ [39].

The current study showed improvement in the efficacy of chitosan nanoparticles versus non-formulated states. For instance, the $\mathrm{IC}_{50}$ value of $M$. spicata $1136 \mu \mathrm{g} / \mathrm{mL}$ against A375 cells was decreased to $143 \mu \mathrm{g} / \mathrm{mL}$ in a nano-formulated state (MSChiNPs). The IC 50 value of carvone against MDA-MB468, $6038 \mu \mathrm{g} / \mathrm{mL}$, was dramatically decreased to $236 \mu \mathrm{g} / \mathrm{mL}$ in the nano-formulated state (CVChiNPs). Existing reports could justify these improvements; e.g., when drugs or EOs are dissolved in their proper solvents, obtained droplet size is around $\leq 2$ $\mathrm{nm}[40,41]$. When drugs or EOs are loaded in a nanocarrier with a particle size of $\sim 200 \mathrm{~nm}$ (such as-prepared chitosan nanoparticles in the current study), about half a million droplets could be incorporated into a particle $[42,43]$; so at lower concentrations compared to nonformulated could show higher efficacy $[44,45]$. Besides, they could easily pass through larger gap junctions of cancer cells with a nanometer size than normal cells [46]. The large surface area and high surface energy of nanocarriers and intrinsic bioadhesive of chitosan nanoparticles also led to better interaction with cells [47, 48]. However, more investigations are recommended for comparing the mode of actions of non-formulated samples vs. their nanoformulated states.

\section{Conclusions}

At first, ingredients of EOs of $M$. spicata and T. balsamita EOs were identified using Gas Chromatography-Mass Spectrometry analysis. Their anticancer activity and carvone (their 
major component) were then evaluated against human melanoma and breast cancer cells (MDA-MB468 and A375). Results demonstrated that M. spicata, T. balsamita EOs, and carvone could inhibit cell proliferation at all examined cells. After that, an attempt was made to improve their efficacy by preparing chitosan nanoparticles containing each. Chitosan nanoparticles containing T. balsamita $\mathrm{EO}$ with $\mathrm{IC}_{50}$ values of 85.3 and $240.1 \mu \mathrm{g} / \mathrm{mL}$ showed the best efficacy against both cell lines; it could thus be considered for further investigations such as in vivo or even supplementary medicine.

\section{Funding}

This study was funded by Fasa University of Medical Sciences, Fasa, Iran (grant number 400057). It has been ethically approved by the ethical committee; IR.FUMS.REC.1400.057.

\section{Acknowledgments}

Not applicable.

\section{Conflicts of Interest}

There is no conflict of interest amongst the authors.

\section{References}

1. World Health Organization. Cancer. https://www.who.int/health-topics/cancer\#tab=tab_1.

2. Ferlay, J.; Ervik, M.; Lam, F.; Colombet, M.; Mery, L.; Piñeros, M.; Znaor, A.; Soerjomataram, I.; Bray, F. Global cancer observatory: Cancer today 2020, Lyon, France: International Agency for Research on Cancer. Available from: https://gco.iarc.fr.

3. World Health Organization. Cancer. https://www.who.int/news-room/fact-sheets/detail/cancer.

4. Sung, H.; Ferlay, J.; Siegel, R.L.; Laversanne, M.; Soerjomataram, I.; Jemal, A.; Bray, F. Global cancer statistics 2020: GLOBOCAN estimates of incidence and mortality worldwide for 36 cancers in 185 countries. CA Cancer J Clin 2021, 71, 209-249, https://doi.org/10.3322/caac.21660.

5. Haider, T.; Pandey, V.; Banjare, N.; Gupta, P.N.; Soni, V. Drug resistance in cancer: mechanisms and tackling strategies. Pharmacol. Rep. 2020, 72, 1125-1151, https://doi.org/10.1007/s43440-020-00138-7.

6. Blowman, K.; Magalhães, M.; Lemos, M.; Cabral, C.; Pires, I. Anticancer properties of essential oils and other natural products. Evidence-based Complement. Evid. Based Complement. Alternat. Med. 2018, 2018, 3149362, https://doi.org/10.1155/2018/3149362.

7. Faraloni, C. Antioxidant Property and Antimicrobial Activity of the Aromatic Plant Balsamita major Desf. International Journal of Clinical \& Medical Microbiology 2018, 3, 3:IJCMM-138, https://doi.org/10.15344/2456-4028/2018/138.

8. Osanloo, M.; Arish, J.; Sereshti, H. Developed methods for the preparation of electrospun nanofibers containing plant-derived oil or essential oil: a systematic review. Polymer Bulletin 2020, 77, 6085-6104, https://link.springer.com/article/10.1007/s00289-019-03042-0.

9. Esmaili, F.; Sanei-Dehkordi, A.; Amoozegar, F.; Osanloo, M. A Review on the Use of Essential Oil-Based Nanoformulations in Control of Mosquitoes. Biointerface Research in Applied Chemistry 2021, 11, 1251612529, https://doi.org/10.33263/BRIAC115.1251612529.

10. Mohammed, M.A.; Syeda, J.T.M.; Wasan, K.M.; Wasan, E.K. An Overview of Chitosan Nanoparticles and Its Application in Non-Parenteral Drug Delivery. Pharmaceutics 2017, 9, 53, https://doi.org/10.3390/pharmaceutics9040053.

11.Zhang, X.; Yang, X.; Ji, J.; Liu, A.; Zhai, G. Tumor targeting strategies for chitosan-based nanoparticles. Colloids and Surfaces B: Biointerfaces 2016, 148, 460-473, https://doi.org/10.1016/j.colsurfb.2016.09.020.

12. Wu, J.; Shu, Q.; Niu, Y.; Jiao, Y.; Chen, Q. Preparation, Characterization, and Antibacterial Effects of Chitosan Nanoparticles Embedded with Essential Oils Synthesized in an Ionic Liquid Containing System. J. Agric. Food Chem. 2018, 66, 7006-7014, https://doi.org/10.1021/acs.jafc.8b01428. 
13. Esmaeili, A.; Asgari, A. In vitro release and biological activities of Carum copticum essential oil (CEO) loaded chitosan nanoparticles. Int. J. Biol. Macromol. 2015, 81, 283-290, https://doi.org/10.1016/j.ijbiomac.2015.08.010.

14. Cappello, G.; Spezzaferro, M.; Grossi, L.; Manzoli, L.; Marzio, L. Peppermint oil (Mintoil) in the treatment of irritable bowel syndrome: a prospective double blind placebo-controlled randomized trial. Dig. Liver Dis. 2007, 39, 530-536, https://doi.org/10.1016/j.dld.2007.02.006.

15. Mahboubi, M. Mentha spicata as natural analgesia for treatment of pain in osteoarthritis patients. Complement. Ther. Clin. Pract. 2017, 26, 1-4, https://doi.org/10.1016/j.ctcp.2016.11.001.

16. Manosroi, J.; Dhumtanom, P.; Manosroi, A. Antiproliferative activity of essential oil extracted from Thai medicinal plants on $\mathrm{KB}$ and $\mathrm{P} 388$ cell lines. Cancer Letter 2006, 235, 114-120, https://doi.org/10.1016/j.canlet.2005.04.021.

17. Hussain, A.I.; Anwar, F.; Nigam, P.S.; Ashraf, M.; Gilani, A.H. Seasonal variation in content, chemical composition and antimicrobial and cytotoxic activities of essential oils from four Mentha species. J. Sci. Food Agric. 2010, 90, 1827-1836, https://doi.org/10.1002/jsfa.4021.

18. Hajighasemi, F.; Khoshzaban, F. Cytotoxic effect of Mentha spicata aqueous extract on cancerous cell lines in vitro. Journal of Medicinal Plants Research 2011, 5, 5142-5147, https://doi.org/10.5897/JMPR.9000423.

19. Nedel, F.; Begnini, K.; Carvalho, P.H.d.A.; Lund, R.G.; Beira, F.T.; Del Pino, F.A.B. Antiproliferative activity of flower hexane extract obtained from Mentha spicata associated with Mentha rotundifolia against the MCF7, KB, and NIH/3T3 cell lines. J. Med. Food 2012, 15, 955-958, https://doi.org/10.1089/jmf.2011.0340.

20. Bardaweel, S.K.; Bakchiche, B.; Alsalamat, H.A.; Rezzoug, M.; Gherib, A.; Flamini, G. Chemical composition, antioxidant, antimicrobial and Antiproliferative activities of essential oil of Mentha spicata L. (Lamiaceae) from Algerian Saharan atlas. BMC Complement Altern Med 2018, 18, 201, https://doi.org/10.1186/s12906-018-2274-X.

21. Kazemzadeh, M.; Yaghmaei, P.; Mohammadi, S. Analgesic and anti-inflammatory effects of Tanacetum balsamita essential oil and one of its major constituents (quercetin) in male rats. Clinical Neurology and NeuroScience 2017, 1, 60-66, http://dx.doi.org/10.11648/j.cnn.20170103.17.

22. Lv, L.; Yang, N.; Cao, Y.; Dang, J.; Cheng, L.; El-Sheikh, M.A.; Zhang, Y. d-Carvone inhibits the JAK/STAT3 signaling pathway and induced the apoptotic cell death in the human gastric cancer AGS cells. J. Biochem. Mol. Toxicol. 2021, 35 , e22746, https://doi.org/10.1002/jbt.22746.

23. Vinothkumar, R.; Nalini, N. Supplementation with D-carvone Induces Cytotoxicity and MitochondrialMediated Apoptosis in Human Colon Cancer Cell Lines HT-29 and SW480. IJPBA 2013, 4, 502-510.

24. Patel, P.B.; Thakkar, V.R. L-carvone induces p53, caspase 3 mediated apoptosis and inhibits the migration of breast cancer cell lines. Nutr. Cancer 2014, 66, 453-462, https://doi.org/10.1080/01635581.2014.884230.

25. MoemenbellahFard, M.D.; Abdollahi, A.; Ghanbariasad, A.; Osanloo, M. Antibacterial and leishmanicidal activities of Syzygium aromaticum essential oil versus its major ingredient, eugenol. Flavour and Fragrance Journal 2020, 35, 534-540, https://doi.org/10.1002/ffj.3595.

26. Alipanah, H.; Farjam, M.; Zarenezhad, E.; Roozitalab, G.; Osanloo, M. Chitosan nanoparticles containing limonene and limonene-rich essential oils: potential phytotherapy agents for the treatment of melanoma and breast cancers. BMC Complementary Medicine and Therapies 2021, 21, 186, https://doi.org/10.1186/s12906021-03362-7.

27. Abedinpour, N.; Ghanbariasad, A.; Taghinezhad, A.; Osanloo, M. Preparation of Nanoemulsions of Mentha piperita Essential Oil and Investigation of Their Cytotoxic Effect on Human Breast Cancer Lines. BioNanoScience 2021, 11, 428-436, https://doi.org/10.1007/s12668-021-00827-4.

28. Karikas, G.A. Anticancer and chemopreventing natural products: some biochemical and therapeutic aspects. Journal of BUON 2010, 15, 627-638.

29. Bisi-Johnson, M.A.; Obi, C.L.; Hattori, T.; Oshima, Y.; Li, S.; Kambizi, L.; Eloff, J.N.; Vasaikar, S.D. Evaluation of the antibacterial and anticancer activities of some South African medicinal plants. BMC Complement Altern Med 2011, 11, 1-5, https://doi.org/10.1186/1472-6882-11-14.

30. Alipanah, H.; Zareian, P. Anti-cancer properties of the methanol extract of Boswellia serrata gum resin: Cell proliferation arrest and inhibition of angiogenesis and metastasis in BALB/c mice breast cancer model. Physiology and Pharmacology 2018, 22, 183-194.

31. Pirmoradian, M.; Budamgunta, H.; Chingin, K.; Zhang, B.; Astorga-Wells, J.; Zubarev, R.A. Rapid and deep human proteome analysis by single-dimension shotgun proteomics. Mol. Cell. Proteomics 2013, 12, 33303338, https://doi.org/10.1074/mcp.o113.028787. 
32. Maksimović-Ivanić, D.; Bulatović, M.; Edeler, D.; Bensing, C.; Golić, I.; Korać, A.; Kaluđerović, G.N.; Mijatović, S. The interaction between SBA-15 derivative loaded with $\mathrm{Ph}_{3} \mathrm{Sn}\left(\mathrm{CH}_{2}\right)_{6} \mathrm{OH}$ and human melanoma A375 cell line: uptake and stem phenotype loss. Journal of Biological Inorganic Chemistry 2019, 24, 223-234, https://doi.org/10.1007/s00775-019-01640-x.

33. Dai, X.; Cheng, H.; Bai, Z.; Li, J. Breast Cancer Cell Line Classification and Its Relevance with Breast Tumor Subtyping. J. Cancer 2017, 8, 3131-3141, https://doi.org/10.7150/jca.18457.

34. Hugo, H.J.; Gunasinghe, N.P.A.D.; Hollier, B.G.; Tanaka, T.; Blick, T.; Toh, A.; Hill, P.; Gilles, C.; Waltham, M.; Thompson, E.W. Epithelial requirement for in vitro proliferation and xenograft growth and metastasis of MDA-MB-468 human breast cancer cells: oncogenic rather than tumor-suppressive role of E-cadherin. Breast Cancer Res. 2017, 19, 86, https://doi.org/10.1186/s13058-017-0880-z.

35. Mohafrash, S.M.; Fallatah, S.A.; Farag, S.M.; Mossa, A-T.H. Mentha spicata essential oil nanoformulation and its larvicidal application against Culex pipiens and Musca domestica. Industrial Crops and Products 2020, 157, 112944, https://doi.org/10.1016/j.indcrop.2020.112944.

36. Shahbazi, Y. Application of carboxymethyl cellulose and chitosan coatings containing Mentha spicata essential oil in fresh strawberries. Int. J. Biol. Macromol. 2018, 112, 264-272, https://doi.org/10.1016/j.ijbiomac.2018.01.186.

37. Shahbazi, Y.; Shavisi, N. Chitosan Coatings Containing Mentha spicata Essential Oil and Zinc Oxide Nanoparticle for Shelf Life Extension of Rainbow Trout Fillets. Journal of Aquatic Food Product Technology 2018, 27, 986-997, https://doi.org/10.1080/10498850.2018.1518945.

38. Azizkhani, M.; Sodanlo, A. Antioxidant activity of Eryngium campestre L., Froriepia subpinnata, and Mentha spicata L. polyphenolic extracts nanocapsulated in chitosan and maltodextrin. Journal of Food Processing and Preservation 2021, 45, e15120, https://doi.org/10.1111/jfpp.15120.

39. Ahmad, B.; Shireen, F.; Bashir, S.; Khan, I.; Azam, S. Green synthesis, characterisation and biological evaluation of AgNPs using Agave americana, Mentha spicata and Mangifera indica aqueous leaves extract. IET nanobiotechnology 2016, 10, 281-287, https://doi.org/10.1049/iet-nbt.2015.0053.

40. Ashbaugh, H.S.; Paulaitis, M.E. Effect of Solute Size and Solute-Water Attractive Interactions on Hydration Water Structure around Hydrophobic Solutes. J. Am. Chem. Soc. 2001, 123, 10721-10728, https://doi.org/10.1021/ja016324k.

41. Carlsson, J.; Åqvist, J. Calculations of solute and solvent entropies from molecular dynamics simulations. Phys. Chem. Chem. Phys. 2006, 8, 5385-5395, https://doi.org/10.1039/B608486A.

42. Prakash, A.; Baskaran, R.; Paramasivam, N.; Vadivel, V. Essential oil based nanoemulsions to improve the microbial quality of minimally processed fruits and vegetables: A review. Food Research International 2018, 111, 509-523, https://doi.org/10.1016/j.foodres.2018.05.066.

43. Das, S.; Singh, V.K.; Dwivedy, A.K.; Chaudhari, A.K.; Deepika; Dubey, N.K. Nanostructured Pimpinella anisum essential oil as novel green food preservative against fungal infestation, aflatoxin $\mathrm{B}_{1}$ contamination and deterioration of nutritional qualities. Food Chem. 2021, 344, 128574, https://doi.org/10.1016/j.foodchem.2020.128574.

44. Liu, Y.; Niu, T-S.; Zhang, L.; Yang, J-S. Review on nano-drugs. Natural Science 2010, 2, 41-48, http://dx.doi.org/10.4236/ns.2010.21006.

45. Havel, H.A. Where are the nanodrugs ? An industry perspective on development of drug products containing nanomaterials. AAPS J. 2016, 18, 1351-1353, https://doi.org/10.1208/s12248-016-9970-6.

46. Peng, F.; Setyawati, M.I.; Tee, J.K.; Ding, X.; Wang, J.; Nga, M.E.; Ho, H.K.; Leong, D.T. Nanoparticles promote in vivo breast cancer cell intravasation and extravasation by inducing endothelial leakiness. Nature Nanotechnology 2019, 14, 279-286, https://doi.org/10.1038/s41565-018-0356-z.

47. Dudhani, A.R.; Kosaraju, S.L. Bioadhesive chitosan nanoparticles: Preparation and characterization. Carbohydrate Polymers 2010, 81, 243-251, http://dx.doi.org/10.1016/j.carbpol.2010.02.026.

48. Pan, Y.; Li, Y-j.; Zhao, H-y.; Zheng, J-m.; Xu, H.; Wei, G.; Hao, J-s.; Cui, Fu-d. Bioadhesive polysaccharide in protein delivery system: chitosan nanoparticles improve the intestinal absorption of insulin in vivo. Int. J. Pharm. 2002, 249, 139-147, https://doi.org/10.1016/s0378-5173(02)00486-6. 